\title{
Concentrate for Oromucosal Solution Dosage Form
}

National Cancer Institute

\section{Source}

National Cancer Institute. Concentrate for Oromucosal Solution Dosage Form. NCI

Thesaurus. Code C149397.

Liquid preparation intended to be diluted in the specified liquid to obtain an oromucosal solution. 